\title{
Sirkulasi film platform streaming di Indonesia ${ }^{1}$
}

\section{Dhevi Enlivena Irene Restia Mahelingga}

Balai Media dan Reproduksi LIPI

\begin{abstract}
Abstrak: Internet di Indonesia senantiasa tumbuh, baik dari teknologi maupun pengguna. Situasi tersebut membuka sirkulasi media yang lebih dinamis, terutama dalam industri perfilman. Platform streaming merupakan salah satu bentuk sirkulasi yang memiliki potensi untuk berkembang dan dimanfaatkan oleh sineas Indonesia. Kekayaan budaya dan keanekaragaman hayati Indonesia menjadi fondasi dalam menghasilkan film bermuatan lokal untuk memperkenalkan Indonesia kepada dunia. Ragam film yang sebelumnya tidak bisa menembus pasar konvensional saat ini bisa disirkulasikan secara bebas melalui platform streaming. Platform streaming juga memiliki kemungkinan masa depan yang luas, tidak hanya dari sisi kuantitas pengaksesnya, tetapi juga kualitas yang tidak kalah dengan media konvensional.
\end{abstract}

Kata kunci: Sirkulasi; film; streaming

Pengguna internet Indonesia terus mengalami perkembangan setiap tahunnya. Asosiasi Penyedia Jasa Internet Indonesia (APJII) menyebutkan hingga kuartal II tahun 2020, jumlah pengguna internet Indonesia mencapai 196,7 juta orang atau 73, 7\% dari total populasi Indonesia menurut BPS, yakni 266, 9 juta jiwa.(Kominfo, 2020; KumparanTECH, 2020) Kenaikan jumlah penggguna tersebut salah satunya disebabkan infrastruktur internet cepat atau broadband di Indonesia semakin merata dengan adanya Palapa Ring. Faktor pandemi Covid-19 juga turut menyebabkan kenaikan penggunaan internet untuk menunjang sejumlah kegiatan yang praktis dilakukan di rumah, baik bekerja, belajar, maupun menikmati hiburan. Di sektor hiburan, data APJII mencatat video daring menjadi akses hiburan terbesar dengan 49,3\%, disusul game daring 16,5\%, dan musik daring 15,3\%.(KumparanTECH, 2020)

Situasi tersebut membuka peluang bagi berkembangnya media baru, yakni dinamika yang membawa persebaran media yang oleh Henry Jenkins, Sam Ford, dan Joshua Green dalam Spreadable media: Creating value and meaning in a networked culture disebut sebagai 'sirkulasi', yang memiliki arti lebih luas dari 'distribusi' yang bersifat top down dan komersial. Sirkulasi merujuk pada penyebaran konten media, baik top-down maupun bottom-up, baik komersial maupun merakyat. Pergeseran dari distribusi ke sirkulasi memberikan sinyal sebuah gerakan menuju budaya yang lebih partisipatif di mana publik bukanlah sekadar konsumen tetapi juga

\footnotetext{
${ }^{1}$ Dipublikasikan di situs web LIPI Press dengan tautan https://lipipress.lipi.go.id/detailpost/sirkulasi-film-platformstreaming-di-indonesia pada 3 Februari 2021.
} 
merupakan pihak yang membentuk, membagi, membingkai, atau mengolah kembali konten media dengan cara-cara yang tidak pernah diimajinasikan sebelumnya.(Anshari, 2019; Jenkins et al., 2013)

Perkembangan internet memungkinkan sirkulasi media baru menjadi semakin sederhana, cepat, dan bebas biaya. Di sisi lain memunculkan dampak negatif dengan maraknya pembajakan melalui situs web unduh film ilegal yang apabila tidak dikendalikan akan mengancam industri perfilman, terutama industri perfilman Indonesia yang saat ini mulai bangkit. Situasi ini tentunya harus ditekan dengan sejumlah langkah strategis, Michael Strangelove dalam Post-TV: Piracy, cord-cutting, and the future of television mencatat bagaimana kemunculan platform streaming legal seperti Hulu dan Netflix menurunkan angka pembajakan situs web film ilegal. Strangelove menunjukkan bahwa kemudahan akses menjadi faktor penting bagi audiens film dalam lingkup media baru di samping faktor ekonomi.(Anshari, 2019; Strangelove, 2015)

Di Indonesia, platform sirkulasi dengan beragam model bisnis berbasis Video on Demand (VoD) telah hadir menggantikan penjualan dan penyewaan DVD/Bluray atau melengkapi siaran TV konvensional. Model berbasis VoD tersebut terus mengalami perkembangan dengan munculnya berbagai jenis turunannya, seperti Transactional Video On Demand (TVoD), Ad-based Video On Demand (AVoD), dan Subscription Video On Demand (SVoD).(Gasella, 2020) Untuk SVOD saja pada 2020, sedikitnya ada delapan penyedia platform yang hadir dan legal di Indonesia, antara lain iFlix, Netflix, Vidio, GoPlay, Genflix, CatchPlay, Viu, dan Disney+ Hotstar. Kehadiran layanan konten internet over the top (OTT) berbasis aplikasi tersebut telah membawa banyak pengaruh pada industri hiburan, khususnya perfilman dunia dan Indonesia.

Bagi masyarakat Indonesia yang memperhatikan biaya dan harga yang harus dikeluarkan dalam pola konsumsinya,(Soliha, 2008) biaya transportasi atau makanan yang harus dikeluarkan saat pergi ke bioskop untuk menikmati film akan menjadi pertimbangan. Pertimbangan tersebut akan dibandingkan dengan kemudahan layanan $\mathrm{VoD}$, mulai dari kepraktisan, jumlah uang yang harus dikeluarkan, hingga tren gaya hidup yang berubah, kehadiran layanan VoD sedikit banyak memengaruhi tingkat kunjungan orang ke bioskop.(Suryanto, 2020) Hal ini membuka peluang berkembangnya media baru berbasis platform menjadi sirkulasi tambahan perfilman di Indonesia secara lebih masif. Meski harus diakui masih belum bisa menggantikan pemasukan dari bioskop, namun pendapatan dalam bisnis SVoD di Indonesia terus tumbuh dan tahun 2020 diperkirakan naik 28,9\% menjadi 140 juta dolar AS, dengan jumlah pelanggan (users) naik 26,5\% menjadi sekitar 13 juta pengguna.(Suryanto, 2020)

Potensi tersebut menjadi ceruk yang bisa dikembangkan oleh para pegiat film dan sineas Indonesia dengan beragam strategi mengingat kemajuan teknologi mendukung produksi konten menjadi jauh lebih dinamis. Dari tataran ide, mengawinkan film dengan kekayaan budaya dan alam Indonesia bisa menjadi cara efektif dalam menarik penonton sekaligus mengangkat Indonesia sebagai negara destinasi wisata, baik alam maupun budaya, dengan cara yang menyenangkan.(Suryanto, 2020) Fungsi komunikasi dan artistik film bisa dimanfaatkan sebagai penyampai pesan dan pembentuk opini yang efektif pada target audiensnya.(Mahelingga, 2021) Dari segi teknis, adanya platform streaming menjadi jalan keluar bagi film yang karena satu dan lain hal tidak dapat tampil di bioskop. Film-film bermuatan lokal dari berbagai belahan dunia yang 
sebelumnya terkendala distribusi bisa diakomodasi melalui sirkulasi platform streaming.(Gasella, 2020) Terlebih adanya dukungan pemerintah melalui Kementerian Kominfo dan Kemenparekraf dengan sejumlah kebijakan terkait perfilman nasional menjadi lampu hijau bagi perkembangan industri ini di masa depan.(Mayasari \& Winarto, 2020; Suryanto, 2020)

Pertumbuhan sirkulasi film dalam platform streaming tentunya diharapkan tidak hanya dari segi kuantitas semata, melainkan dari segi kualitas. Salah satu yang patut dicermati adalah dengan diakuinya film platform streaming untuk bersaing di Academy Awards atau Oscar tahun 2021. Sebelumnya hal tersebut sangat ditentang dalam aturan konservatif Academy Awards yang mengharuskan film diputar di bioskop minimal tujuh hari berturut-turut.(Pradana, 2020) Meskipun disebutkan keputusan berlaku khusus tahun 2021 karena dampak pandemi Covid-19 dan mendapat kritikan terkait kekhawatiran penilaian menjadi tidak maksimal karena akses streaming tidak akan bisa menyamai standar bioskop(Kilday \& Giardina, 2021), namun hal ini bisa menjadi tonggak sejarah bahwa film yang disirkulasikan di platform streaming memiliki kemungkinan masa depan yang lebih luas. Film sirkulasi platform streaming tidak hanya berpeluang dari sisi kuantitas dengan kemudahan akses untuk dinikmati oleh lebih banyak orang di seluruh penjuru dunia, tetapi secara kualitas bisa bersaing dengan film-film di jalur konvensional.

\section{Referensi}

Anshari, I. N. (2019). Sirkulasi Film dan Program Televisi di Era Digital: Studi Kasus Praktik Download dan Streaming melalui Situs Bajakan. Komuniti: Jurnal Komunikasi Dan Teknologi Informasi, 10(2), 88-102. https://doi.org/10.23917/komuniti.v10i2.7125

Gasella, S. (2020). Dinamika Distribusi Film di Era Platform Streaming yang Semakin Booming. Kumparan.Com. https://kumparan.com/shandy-gasella/dinamika-distribusi-film-di-eraplatform-streaming-yang-semakin-booming-1uNNDr45BCs

Jenkins, H., Ford, S., \& Green, J. (2013). Spreadable media: Creating value and meaning in a networked culture. Spreadable Media: Creating Value and Meaning in a Networked Culture, 53(3), 1-352. https://doi.org/10.3983/twc.2014.0633

Kilday, G., \& Giardina, C. (2021). Oscar Contenders Worry Screening by Streaming Does Their Films an Injustice. Hollywood Reporter. https://www.hollywoodreporter.com/news/oscarcontenders-worry-screening-by-streaming-does-their-films-an-injustice

Kominfo. (2020). Dirjen PPI: Survei Penetrasi Pengguna Internet di Indonesia Bagian Penting dari Transformasi Digital. Kominfo. https://kominfo.go.id/content/detail/30653/dirjen-ppisurvei-penetrasi-pengguna-internet-di-indonesia-bagian-penting-dari-transformasidigital/0/berita_satker

KumparanTECH. (2020). Jumlah Pengguna Internet Indonesia Tahun 2020 Capai 196,7 Juta, Naik karena WFH. Kumparan.Com. https://kumparan.com/kumparantech/jumlahpengguna-internet-indonesia-tahun-2020-capai-196-7-juta-naik-karena-wfh1uYnJ729dTL/full

Mahelingga, D. E. (2021). REPRESENTASI 'KAFIR'DALAM FILM HOROR INDONESIA. JADECS (Jurnal of Art, Design, Art Education \& Cultural Studies), 5(2), 86-95. https://doi.org/10.17977/um037v5i2p86-95 
Mayasari, S., \& Winarto, Y. (2020). Kemenparekraf dukung platform digital lokal untuk jadi alternatif distribusi film. Kontan. https://industri.kontan.co.id/news/kemenparekraf-dukungplatform-digital-lokal-untuk-jadi-alternatif-distribusi-film

Pradana, B. (2020). Film di Platform Streaming Boleh Ikut Seleksi Piala Oscar 2021. Media Indonesia. https://mediaindonesia.com/weekend/308784/film-di-platform-streaming-bolehikut-seleksi-piala-oscar-2021

Soliha, E. (2008). Analisis Industri Ritel di Indonesia. Jurnal Bisnis Dan Ekonomi (JBE), 15(2), $128-143$.

Strangelove, M. (2015). Post-TV: Piracy, cord-cutting, and the future of television. University of Toronto Press.

Suryanto. (2020). Layanan Streaming tantangan dan peluang perfilman Indonesia. Antaranews. https://www.antaranews.com/berita/1776245/layanan-streaming-tantangan-dan-peluangperfilman-indonesia 